\title{
Use of Red Cactus Pear (Opuntia ficus-indica) Encapsulated Powder to Pigment Extruded Cereal
}

\author{
Martha G. Ruiz-Gutiérrez, ${ }^{1}$ Carlos A. Amaya-Guerra, ${ }^{2}$ Armando Quintero-Ramos, \\ Esther Pérez-Carrillo, ${ }^{3}$ and Carmen O. Meléndez-Pizarro ${ }^{1}$ \\ ${ }^{1}$ Departamento de Investigación y Posgrado, Facultad de Ciencias Químicas, Universidad Autónoma de Chihuahua, \\ Circuito Universitario s/n Campus Universitario 2, 31125 Chihuahua, CHIH, Mexico \\ ${ }^{2}$ Departamento de Investigación y Posgrado, Facultad de Ciencias Biológicas, Universidad Autónoma de Nuevo León, \\ Ciudad Universitaria, 66450 San Nicolás de los Garza, NL, Mexico \\ ${ }^{3}$ Centro de Biotecnología-FEMSA, Escuela de Ingeniería y Ciencias, Tecnológico de Monterrey, \\ Av. Eugenio Garza Sada 2501 Sur, 64849 Monterrey, NL, Mexico
}

Correspondence should be addressed to Carlos A. Amaya-Guerra; numisamaya@hotmail.com

Received 27 April 2017; Revised 19 September 2017; Accepted 15 October 2017; Published 15 November 2017

Academic Editor: Encarna Aguayo

Copyright (c) 2017 Martha G. Ruiz-Gutiérrez et al. This is an open access article distributed under the Creative Commons Attribution License, which permits unrestricted use, distribution, and reproduction in any medium, provided the original work is properly cited.

\begin{abstract}
Encapsulated powder of the red cactus pear is a potential natural dye for the food industry and a known antioxidant. Although the use of this powder is possible, it is not clear how it alters food properties, thus ensuing commercial acceptability. The aim of this study was to evaluate the effect of encapsulated powder of the red cactus pear on the physicochemical properties of extruded cereals. The powder was mixed $(2.5,5.0$, and $7.5 \% \mathrm{w} / \mathrm{w})$ with maize grits and extruded (mix moisture $22 \%$, temperature $100^{\circ} \mathrm{C}$, and screw speed $325 \mathrm{rpm}$ ). The physical, chemical, and sensory characteristics of the extruded cereal were evaluated; extruded cereal without encapsulated powder was used as a control. All cereal extrudates pigmented with the encapsulated powder showed statistically significant differences $(P<0.05)$ in expansion, water absorption, color, density, and texture compared to the control. The encapsulated powder had a positive effect on expansion and water absorption indices, as well as color parameters, but a negative effect on density and texture. Extruded cereal properties were significantly $(P<0.05)$ correlated. Sensorially, consumers accepted the extruded cereal with a lower red cactus pear powder content $(2.5 \% \mathrm{w} / \mathrm{w})$, because this presented characteristics similar to extruded cereal lacking pigment.
\end{abstract}

\section{Introduction}

The percentage of consumers who are paying attention to food labels is increasing; this increase is related to the presence of chemical additives in processed food and their potentially negative effects on health [1]. To meet the challenge, food producers have turned to natural or organic ingredients. However, this is a complex issue, as the food must have sensorial characteristics that are attractive to the consumer. An important food property is color, because this is the first attribute of the product perceived by the consumer and therefore it can be a decisive factor for food acceptance or rejection. Food pigmentation is a practice that goes back to ancient times [2]; however, currently, most foods are formulated using synthetic pigments, as they possess advantages over natural pigments such as stability under certain processes and storage conditions. Among the factors affecting pigment stability, and therefore the natural pigment color, are $\mathrm{pH}$, water content, presence of oxygen, and temperature $[3,4]$. Temperature is the main determinant, as food processing is often based on the application of heat. A very important color in the food industry is red, which is used in many products, such as cookies, pastries, candies, cereals, yogurt, dairy drinks, ice creams, snacks, jams, juices, nonalcoholic drinks, nectars, puree, condiments, prepared flours, and meat products. Red color is achieved through the use of synthetic pigments, such as aborigine, amaranth, red rondeau, erythrosine, red $2 \mathrm{G}$, and red allure as well as the 
natural pigment red carmine. All of these dyes have been associated with allergic reactions and other diseases, although controversy still exists [2]. Among commercial pigments, betanin figures as a naturally sourced red pigment. It is the most important pigment of the betalains family and belongs to the betacyanins group characterized by a redpurple color, such as that extracted from beetroot. Unlike synthetic pigments, betanin is known to have a beneficial effect on consumer health, but it imparts a certain undesirable flavor and has poor stability. For this reason, other natural red pigments and/or sources need to be investigated. Red cactus pear is a source of betanin, as well as other betalainic pigments such as betaxanthins (yellow pigments). The use of red cactus pear as a pigment has a strong potential, also because it contains bioactive compounds that could benefit consumer health $[5,6]$. Encapsulation is a technology that enables control over the release of bioactive components such as carotenoid pigments and can reduce their thermal degradation [7]. Encapsulation by the spray-drying method has been applied to obtain powder from the red cactus pear using either soluble fiber [8] or maltodextrin [9] as carriers. Ruiz-Gutiérrez et al. [10] have used the encapsulated powder of the red cactus pear in extrusion cooking and were able to obtain a wide range of products. Although this process involves the use of high temperatures and may be too severe for thermosensitive compounds and their functionality, high retention of bioactive compounds and pigments was reported even under such elevated temperature conditions. This makes encapsulated red cactus pear powder a promising natural pigment compared with other natural pigments such as anthocyanins [11-13]. Studies have demonstrated that additives used as powders, extracts, concentrates, or byproducts from different sources can substantially change the food's physical characteristics and thus potentially affect its acceptability. Such characteristics include water absorption index, bulk density, water solubility index, expansion index, texture, and color [14-17]. The aim of the present study was to evaluate the changes in these physicochemical properties following the addition of 2.5, 5.0, and 7.5\% (w/w) red cactus pear encapsulated powder to pigment extruded cereal.

\section{Materials and Methods}

2.1. Materials Used in Extrusion Cooking. The food matrix used for the extrusion-cooking process was maize grits number 20 (GPC, Muscatine, IA, USA). Red cactus pear encapsulated powder was obtained according to the method reported by Ruiz-Gutiérrez et al. [10]. Red cactus pears (Opuntia ficus-indica) from the Puebla region of Mexico were washed and disinfected using a chlorine solution (150 ppm). Fruits were juiced and the liquid was vacuum-filtered (number 1; Whatman, Kent, UK). The clarified juice $(1 \mathrm{~L})$ was mixed with $22.5 \%(\mathrm{w} / \mathrm{v})$ of soluble fiber [ $(1-3)(1-4)-\beta$-D-glucan from barley] at room temperature and homogenized for $10 \mathrm{~min}$ with an Ultra-Turrax IKA T18 Basic homogenizer with a S18N-19G dispersing tool (IKA Works Inc., Wilmington, NC, USA). The mixture was passed through a spray dryer to obtain a powder. Spray drying was performed using a
Niro Mobile Minor DK-2860 pilot plant spray dryer (GEA Company, Søborg, Denmark) with a rotary atomizer at an air pressure of 4.5 bar. The mixture was fed through a peristaltic pump (Watson Marlow 504-U; Falmouth, Cornwall, UK) and dried at $160^{\circ} \mathrm{C}$ (inlet temperature) and $85^{\circ} \mathrm{C}$ (outlet temperature). Powder from the outlet was stored for subsequent physical and chemical analyses. The encapsulated powder had the following characteristics: moisture content of $0.924 \% \pm 0.159 \%$, water activity of $0.103 \pm 0.02$, pH of $5.53 \pm$ 0.029 , bulk density of $0.622 \pm 0.096 \mathrm{~g} / \mathrm{mL}$, water solubility index of $0.711 \pm 0.049$, and color parameters of $43.27 \pm$ $2.99\left(L^{*}\right), 38.18 \pm 1.74\left(a^{*}\right)$, and $-5.50 \pm 0.2\left(b^{*}\right)$. Chemical characteristics included an antioxidant activity of $5.86 \pm 0.34$ (Trolox equivalent $\mathrm{mmol} / 100 \mathrm{~g}$ ), total polyphenol content of $15.2 \pm 0.56$ (gallic acid equivalent $\mathrm{mg} / \mathrm{g}$ ), a betaxanthin content of $0.6096 \pm 0.03(\mathrm{mg} / \mathrm{g})$, and a betacyanin content of $1.5037 \pm 0.29(\mathrm{mg} / \mathrm{g})$.

2.2. Experimental Procedure. Mixtures of maize grits and encapsulated powder of the red cactus pear $(2.5,5.0$, and $7.5 \%$ w/w) were used to produce extruded cereal products. Maize grits without encapsulated powder were used as a control. The mixtures were extruded using a twin-screw corotating extruder (BCTM-30, Bühler, Uzwil, Switzerland) with a 600 mm length and $L / D=20$. The dye diameter was $4 \mathrm{~mm}$, and the screw configuration was selected specifically to create high levels of shear [18]. The mixture was processed at a fixed amount of feed water $(0.22 \mathrm{~kg}$ water $/ \mathrm{kg}$ dry matter $)$, a barrel temperature of $100^{\circ} \mathrm{C}$, and a screw speed of $325 \mathrm{rpm}$. The extrudates were dried at $60^{\circ} \mathrm{C}$ in an air convection oven (Edel Ingenieros, Monterrey, Mexico). Extruded cereal was used to evaluate texture properties, such as hardness and crispness, and water and milk absorption kinetics. Extruded cereal was milled and sieved $(0.25 \mathrm{~mm})$ to evaluate chemical properties, such as antioxidant activity, total polyphenols, betacyanins, and betaxanthins content, as well as physical properties, such as color parameters $\left(L^{*}, a^{*}, b^{*}\right.$, chroma ${ }^{*}$, and $h^{\circ}$ ), apparent bulk density, expansion index, water absorption index, solubility index, and kinetics of water and milk absorption. Another extrudate portion was covered with a sugar solution $\left(74^{\circ}\right.$ Brix), bagged, and stored at room temperature until sensory evaluation.

\subsection{Physical Analysis}

2.3.1. Moisture Content. The moisture content was determined using the gravimetric method 950.02 [19]. The analysis was carried out in triplicate, and results are expressed in $\mathrm{g} / 100 \mathrm{~g}$ of extruded cereal.

2.3.2. Color Parameters. Color composition was determined using a Konica Minolta CR-400/410 colorimeter (Minolta Co., Osaka, Japan), calibrated with a tile standard with the following values: $X=94.9, y=0.3185$, and $x=0.3124$. The space color used was CIE Lab: $L^{*}$ (lightness), $a^{*}$ (greennessredness), and $b^{*}$ (blueness-yellowness); the determinations were carried out in triplicate. Chroma ${ }^{*}$, hue angle $\left(h^{\circ}\right)$, and 
color difference $\left(\Delta E^{*}\right)$ were calculated using the following equations, respectively [20]:

$$
\begin{aligned}
\operatorname{Chroma}^{*} & =\left(a^{* 2}+b^{* 2}\right)^{1 / 2}, \\
h^{\circ} & =\arctan \left(\frac{b^{*}}{a^{*}}\right), \\
\Delta E^{*} & =\left[\left(L_{c}^{*}-L^{*}\right)+\left(a_{c}^{*}-a^{*}\right)+\left(b_{c}^{*}-b^{*}\right)\right]^{1 / 2},
\end{aligned}
$$

where $L_{c}^{*}, a_{c}^{*}$, and $b_{c}^{*}$ values correspond to control extruded cereal.

2.3.3. Apparent Bulk Density. This property was determined using the method reported by Kha et al. [21] and was based on measuring the weight of a constant volume of extruded cereal.

2.3.4. Expansion Index. The expansion index was calculated following the method reported by Altan et al. [15]. The sectional expansion (width and thickness) of fifteen extruded pieces was randomly measured. The sectional expansion index was calculated using the equation:

$$
\mathrm{SEI}=\frac{S_{e}}{S_{d}}=\frac{W_{e} h_{e}}{W_{d} h_{d}}
$$

where $S_{e}$ and $S_{d}$ are the sectional areas of extruded cereal and die, $W_{e}$, and $h_{e}$ are the width and thickness of the extruded cereal, and $W_{d}$ and $h_{d}$ are the width and thickness of the die, respectively.

2.3.5. Water Absorption Index (WAI). This property was determined according to the method described by Altan et al. [15]. WAI is the weight of gel obtained per gram of dry sample. The screened extrudate was suspended in water at room temperature $\left(25^{\circ} \mathrm{C}\right)$ at a $1: 10$ ratio, stirred for $10 \mathrm{~min}$, and the supernatant was decanted by centrifugation at $1000 \times \mathrm{g}$ for $15 \mathrm{~min}$. The WAI was calculated as the sediment weight after supernatant removal per unit solid weight.

2.3.6. Water Solubility Index (WSI). WSI was determined according to the method described by Altan et al. [15]. The WSI is the weight of the dry solid in the supernatant expressed as a percentage of the original weight of the sample on a dry basis. The sample was suspended in water at room temperature $\left(25^{\circ} \mathrm{C}\right)$ at a $1: 10$ ratio, stirred for $10 \mathrm{~min}$, and centrifuged at $1000 \times \mathrm{g}$ for $15 \mathrm{~min}$, the supernatant was decanted and evaporated, and the weight of the dry solid was obtained.

2.3.7. Texture. Hardness and crispness were evaluated according to the method described by Ding et al. [22], using a TA-XT2 texture analyzer (Stable Micro Systems Ltd., Godalming, Surrey, UK) equipped with a $2 \mathrm{~mm}$ punch, to generate a force-time curve. The curve was analyzed with the Texture Exponent 32 program (Stable Micro Systems Ltd.) to calculate the maximum force $(\mathrm{N})$ that corresponded to the hardness and the area under the curve $(\mathrm{N} / \mathrm{mm})$ that defined crispness. Ten extruded cereals were taken randomly from each treatment.

2.3.8. Kinetics of Water and Milk Absorption. Kinetics analysis was performed according to the method described by Machado et al. [23]. The extruded cereal was immersed in water at $4^{\circ} \mathrm{C}$ for $2 \mathrm{~h}$, and the weight gained by the cereal was recorded after 2, 5, 10, 20, 40, 60, 90, and $120 \mathrm{~min}$, after removing excess liquid. This procedure was also carried out with milk at $4^{\circ} \mathrm{C}$. The data were used to generate water and milk absorption curves, from which to determine the change in absorption of liquid.

\subsection{Chemical Analysis}

2.4.1. Extract Preparation. To determine polyphenol content and antioxidant activity, extracts were obtained according to a method reported by Pitalua et al. [24], with some modifications. Briefly, extruded cereal $(2.5 \mathrm{~g})$ was dispersed in a mixture of methanol and deionized water $(25 \mathrm{~mL}, 1: 1$, $\mathrm{v} / \mathrm{v})$. The dispersion was homogenized for $15 \mathrm{~s}$ using an UltraTurrax IKA T18 Basic homogenizer equipped with a S18N19G dispersing tool. The mixture was centrifuged at $3000 \times \mathrm{g}$ for 10 min in a Centra CL3R IEC centrifuge (Thermo Electron Corp., Waltham, MA, USA); the procedure was repeated to ensure complete extraction. The supernatant was collected and filtered through a polyethylene filter with a pore size of $0.22 \mu \mathrm{m}$ (EMD Millipore Corp., Billerica, MA, USA) and then stored at $-20^{\circ} \mathrm{C}$ until analysis.

2.4.2. Total Polyphenol Content. The total polyphenol content was determined spectrophotometrically using the FolinCiocalteu method reported by Bucić-Kojić et al. [25]. Mixtures were prepared by combining the extract $(0.2 \mathrm{~mL})$ with deionized water $(1.8 \mathrm{~mL})$, Folin-Ciocalteu reagent $(10 \mathrm{~mL}, 10$ fold diluted), and a sodium carbonate solution (8 mL, 7.5\%). The mixtures were vortexed for $10 \mathrm{~s}$ and incubated in a water bath at $45^{\circ} \mathrm{C}$. After $15 \mathrm{~min}$, the reaction was stopped by transferring to a water/ice bath, and absorbance was measured at $765 \mathrm{~nm}$ on a Lambda $25 \mathrm{UV}$-Vis spectrophotometer (Perkin Elmer, Waltham, MA, USA). The measurements were performed in triplicate, and the polyphenol content was calculated from a calibration curve using gallic acid as a standard. The results were expressed as mg gallic acid equivalent/g of extruded cereal.

2.4.3. Antioxidant Activity. A spectrophotometric method reported by Kuskoski et al. [26] based on the measurement of absorbance of the $\mathrm{DPPH}^{*}$ radical was used. First, the extract $(0.1 \mathrm{~mL})$ was added to a $\mathrm{DPPH}^{*}$ radical solution $(3.9 \mathrm{~mL}, 100 \mu \mathrm{M})$, shaken, and stored in the dark for $3 \mathrm{~h}$. Absorbance was measured at $517 \mathrm{~nm}$ using a Lambda $25 \mathrm{UV}$ Vis spectrophotometer. A Trolox standard calibration curve $(0.08-1.28 \mathrm{mM})$ was used to calculate antioxidant activity. Measurements were performed in triplicate, and the results were expressed as mmol Trolox equivalent $/ 100 \mathrm{~g}$ of extruded cereal. 
2.4.4. Betalain Extraction. Betalain pigments were extracted using a method reported by Castellanos-Santiago and Yahia [27], with some modifications. Briefly, the extrudate $(2.5 \mathrm{~g})$ was mixed with deionized water $(25 \mathrm{~mL})$ and stirred for $15 \mathrm{~s}$ using an Ultra-Turrax IKA T18 Basic homogenizer equipped with a S18N-19G dispersing tool. Samples were centrifuged at $3600 \times \mathrm{g}$ at $10^{\circ} \mathrm{C}$ for $40 \mathrm{~min}$ in a Centra CL3R IEC centrifuge; this procedure was repeated to ensure complete extraction. Supernatants were filtered through a $0.45 \mu \mathrm{m}$ nylon filter (EMD Millipore Corp.). Extractions were performed in triplicate, and the extracts were analyzed by photometric methods.

2.4.5. Betalain Quantification. The betalain content (BT) was determined photometrically following a method described by Castellanos-Santiago and Yahia [27], using a Lambda 25 UV-Vis spectrophotometer (Perkin Elmer). The betacyanin content and betaxanthin content were calculated using the following equation:

$$
\mathrm{BT}[\mathrm{mg} / \mathrm{g}]=\left[\frac{A(\mathrm{DF})(\mathrm{Mw}) V_{d}}{\varepsilon L W_{d}}\right],
$$

where $A$ is the absorption value at the absorption maxima of 535 and $483 \mathrm{~nm}$ for betacyanins and betaxanthins, respectively; DF is the dilution factor; $V_{d}$ is the dried pulp solution volume $(\mathrm{mL}) ; W_{d}$ is the dried pulp weight $(\mathrm{g})$; and $L$ is the path length $(1 \mathrm{~cm})$ of the cuvette. For quantification of betacyanin and betaxanthin content, we used the molecular weight $(\mathrm{Mw})$ and molar extinction coefficient $(\varepsilon)$ of betanin $(\mathrm{Mw}=550 \mathrm{~g} / \mathrm{mol} ; \varepsilon=60,000 \mathrm{~L} / \mathrm{mol} \cdot \mathrm{cm}$ in water; $\lambda=536 \mathrm{~nm})$ and indicaxanthin $(\mathrm{Mw}=308 \mathrm{~g} / \mathrm{mol} ; \varepsilon=48,000 \mathrm{~L} / \mathrm{mol} \cdot \mathrm{cm}$ in water; $\lambda=481 \mathrm{~nm}$ ), respectively. The measurements were performed in triplicate, and the results were expressed as mg betacyanin/100 $\mathrm{g}$ extrudate and $\mathrm{mg}$ betaxanthin/100 $\mathrm{g}$ extrudate.

2.5. Sensorial Analysis. A consumer panel of thirty people from Universidad Autónoma de Chihuahua and surrounding areas participated in this sensory test; the panel consisted of 14 males and 16 females. First, panelists were asked to evaluate the sensory attributes: color, aroma, flavor, and texture after-taste of each of the four extruded cereals, which were randomly served. Extruded cereals were served either with or without milk. Sensory attributes were evaluated using a five-point hedonic rating scale: 1 = dislike very much, 2 = dislike moderately, $3=$ neither like nor dislike, $4=$ like moderately, and $5=$ like very much. Also, panelists were asked to order the extruded cereals according to their preference from $1=$ most preferred to $4=$ least preferred.

2.6. Statistical Analysis. A completely randomized design was used (Table 1), and experimental data were analyzed using the Minitab version 17 software [28]. Analysis of variance (ANOVA) and means comparisons were assessed by Tukey's test at $95 \%$ significance level. Sensory data were analyzed by Friedman's test at 95\% significance level. Pearson's correlation coefficients were calculated to determine the relationship between properties of extruded cereal at 0.05 significance.
TABLE 1: Experimental desing* to obtain extruded cereal using encapsulated powder of red cactus pear (EPRCP) as pigment.

\begin{tabular}{lccc}
\hline Run & Order run & Replica & EPRCP $(\%)$ \\
\hline 1 & 6 & 1 & 5.0 \\
2 & 8 & 1 & 7.5 \\
3 & 3 & 1 & 2.5 \\
4 & 2 & 1 & 0.0 \\
5 & 7 & 2 & 7.5 \\
6 & 5 & 2 & 5.0 \\
7 & 4 & 2 & 2.5 \\
8 & 1 & 2 & 0.0 \\
\hline
\end{tabular}

${ }^{*}$ Minitab version 17 software [28].

\section{Results and Discussion}

As shown in Figure 1, four extruded cereals were obtained using different quantities of red cactus fruit encapsulated powder. As the content of encapsulated powder increased notable changes could be observed to the color and expansion of the extruded cereal. The results of physical and chemical properties are shown below.

3.1. Physical Analysis. The moisture content of the extruded cereal was not significantly affected $(P>0.05)$ by addition of the encapsulated powder to the extrusion mixture; this was to be expected since all of the extrudates were dried under the same conditions, and the moisture content for the extrudates was $9.3 \%$ (Table 2). This same trend was observed by Khanal et al. [14], whereby different percentages of cactus fruit concentrates were tested.

Another property that did not show a significant $(P>$ 0.05 ) dependence on the added encapsulated powder was the WSI, with values close to 0.24 (Table 2 ). These values were lower than the index reported in extrudates obtained using bran cassava [29] but higher than those reported in the extrusion process used to obtain extruded snacks [15, 30]. This parameter was likely unaffected because solubility is given by the amount of soluble molecules present in the extrudate and these soluble molecules are the product of starch degradation that occurred during the extrusion process. It has been reported, elsewhere, that the extrusion conditions that cause starch degradation are screw speed [31] and barrel temperature [32], and both variables were fixed in the present study.

In contrast, the bulk density of the extruded cereal was significantly affected $(P<0.05)$ by the content of encapsulated powder added to the mixture; density values are shown in Table 2 and ranged from 0.08 to $0.31 \mathrm{~g} / \mathrm{cm}^{3}$. As the encapsulated powder content increased, the bulk density of extruded cereals increased. Encapsulated powder in the mixture favors the presence of sugars, fibers, and other compounds such as pigments that replace starch [33], preventing expansion and increasing cereal density. In addition, the presence of compounds such as polyphenols, or compounds with hydroxyl groups (betalains) that can form a complex with starch [34], helps compact the cereal matrix to increase 
TABLE 2: Physical properties* of extrudates using encapsulated powder of red cactus pear (EPRCP) as pigment.

\begin{tabular}{lccccc}
\hline EPRCP $(\%)$ & MC $(\%)$ & ABD $\left(\mathrm{g} / \mathrm{cm}^{3}\right)$ & EI & WSI & WAI \\
\hline 0 & $9.41 \pm 0.02^{\mathrm{a}}$ & $0.081 \pm 0.001^{\mathrm{d}}$ & $11.6 \pm 0.7^{\mathrm{a}}$ & $0.24 \pm 0.01^{\mathrm{a}}$ & $6.04 \pm 0.04^{\mathrm{a}}$ \\
2.5 & $9.35 \pm 0.01^{\mathrm{a}}$ & $0.106 \pm 0.001^{\mathrm{c}}$ & $9.43 \pm 0.8^{\mathrm{b}}$ & $0.24 \pm 0.01^{\mathrm{a}}$ & $5.87 \pm 0.11^{\mathrm{a}}$ \\
5.0 & $9.32 \pm 0.06^{\mathrm{a}}$ & $0.210 \pm 0.001^{\mathrm{b}}$ & $6.18 \pm 0.6^{\mathrm{c}}$ & $0.23 \pm 0.01^{\mathrm{a}}$ & $5.23 \pm 0.08^{\mathrm{b}}$ \\
7.5 & $9.34 \pm 0.01^{\mathrm{a}}$ & $0.309 \pm 0.002^{\mathrm{a}}$ & $4.66 \pm 0.2^{\mathrm{d}}$ & $0.23 \pm 0.01^{\mathrm{a}}$ & $4.81 \pm 0.13^{\mathrm{c}}$ \\
\hline
\end{tabular}

${ }^{*}$ Mean \pm standard deviation; mean with different letter by column represents significant $(P<0.05)$ difference by Tukey's test. MC $=$ moisture content; ABD = apparent bulk density; $\mathrm{EI}$ = expansion index; $\mathrm{WAI}=$ water absorption index; WSI = water solubility index.

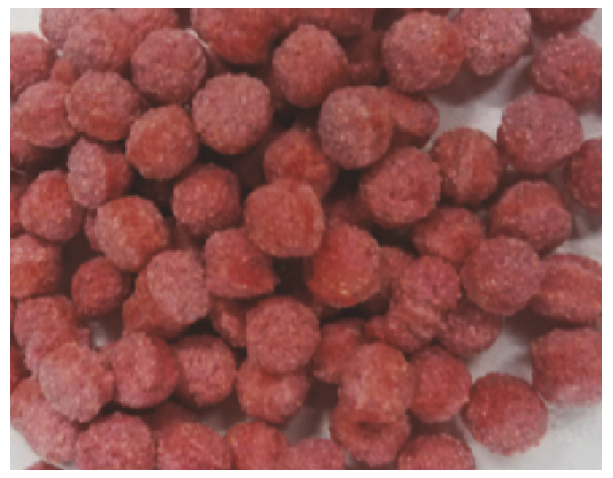

(a)

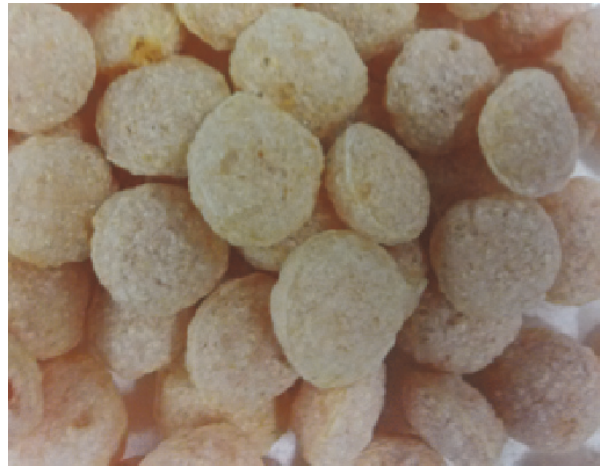

(c)

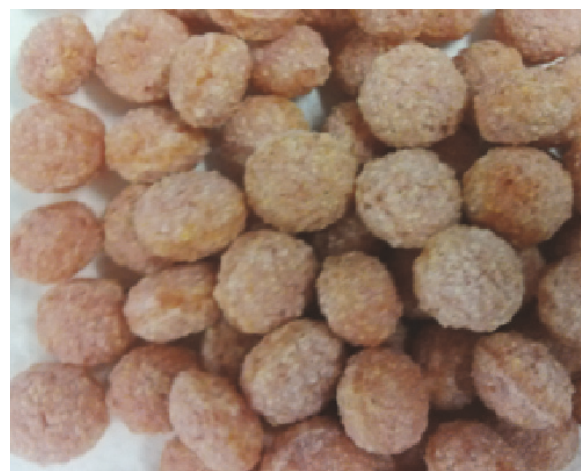

(b)

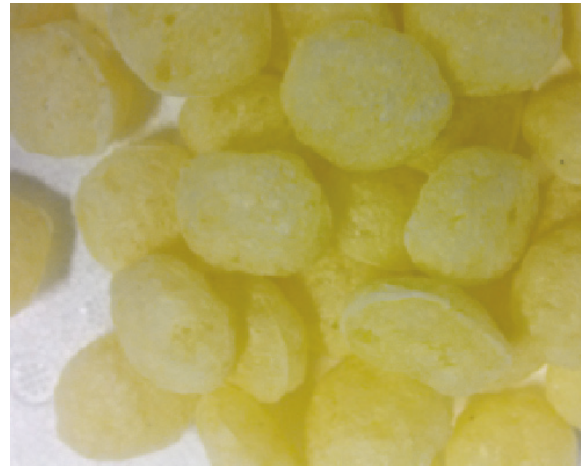

(d)

FIGURE 1: Extruded cereal pigmented with different content of encapsulated powder of red cactus pear; (a) $7.5 \%$, (b) $5.0 \%$, (c) $2.5 \%$, and (d) $0 \%$.

the efficiency of molecular packing [35]. Similar results were obtained by Altan et al. [15], who reported that increases in tomato pulp levels caused an increase in extrudate bulk density, and by Khanal et al. [14]. High bulk density values can increase hardness, and this can affect acceptability by consumers.

Another cereal characteristic that was significantly $(P<$ 0.05 ) affected by the encapsulated powder added to the extrusion mixture was expansion index. The expansion index is related to the size, number, and distribution of air chambers surrounded by the baked matrix [36]. Index values ranged from 4.66 to 11.6 (Table 2), in line with those (6 to 10.5) reported by Yanniotis et al. [37] in extrudates elaborated using starch/pectin/fiber and by Ali et al. [38] in corn semolina extrusion. An increase in the content of encapsulated powder caused a decrease in cereal expansion; this tendency may be due to the dilution effect caused by the encapsulated powder in starch $[14,15]$. It should be noted that the cereal expansion index can be lowered by the presence of other polysaccharides, which can hydrate and compete with starch for water at the extruder outlet, thereby restricting the starch gelatinization process $[14,15,37]$.

The WAI showed the same behavior as the expansion index; it was significantly reduced $(P<0.05)$ by increasing doses of encapsulated powder in the extrusion mixture. WAI values ranged from 4.81 to 6.04 (Table 2). This effect has been reported by other authors in different types of extrudates $[15,32]$ and has been attributed to dilution of the starch content in the cereal. Additionally, the soluble fiber present in the encapsulated powder may have competed with starch for water at the time of expansion at the extruder outlet. This would negatively affect starch gelatinization and dextrinization, leading to extruded cereal with a lower water absorption capacity [15]. Another possible explanation for the 


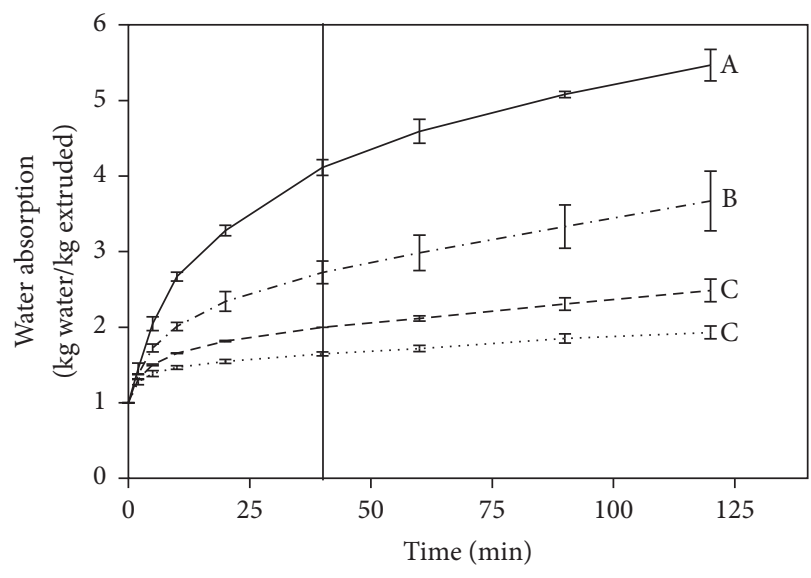

(a)

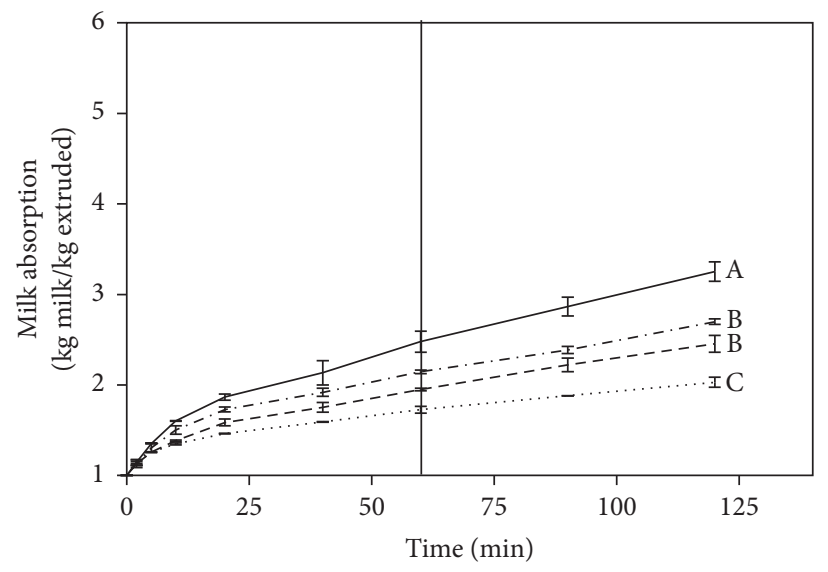

(b)

Figure 2: Absorption kinetics of: (a) water and (b) milk, of extruded cereals pigmented with $-0 \%,-\cdot-2.5 \%,---5.0 \%$, and $\cdots 7.5 \%$ of encapsulated powder of red cactus pear; different upper case letter indicates significant difference $(P<0.05)$ between kinetics in the same medium. Small letter indicates significant difference $(P<0.05)$ between water and milk absorption.

decrease in the WAI following the addition of red cactus pear encapsulated powder is that compounds, such as polyphenols and pigments, present in the encapsulated powder, may interact with the matrix. Such interaction occurs through noncovalent bonding with amylose, leading to changes in textural properties of starch, affecting its gelatinization and retrogradation. In addition, the presence of hydroxylcontaining compounds would increase hydrogen bonding, which could promote a stronger interaction with gelatinized starch $[34,39]$. The formation of these different types of noncovalent interactions creates complexes that affect the properties of the extruded cereal.

The WAI offers a reference for the amount of water that can be absorbed by the extruded products. However, this test is performed on the ground product and does not indicate how absorption occurs when the whole cereal is immersed in a liquid medium. The general way of consuming the extruded cereal product is at breakfast using milk; therefore, water and milk absorption kinetics were examined using whole extruded cereal coated with sucrose, which is how many of the ready-to-eat cereals are prepared.

The water and milk absorption kinetics are shown in Figure 2. Absorption kinetics were performed at $4^{\circ} \mathrm{C}$, as this is the storage temperature of milk. As with the WAI (Table 2), water absorption kinetics (Figure 2(a)) revealed a significantly $(P<0.05)$ reduced capacity to absorb water following increased addition of encapsulated powder to the extrusion mixture. Again, this effect can be explained by (a) the presence of soluble fiber competing with starch for water at the time of extrusion or (b) the formation of a complex between starch and hydroxyl groups of compounds, such as polyphenols and betalains [34]. Both phenomena negatively affect starch gelatinization and dextrinization, leading to the production of extruded cereal with a lower capacity to absorb water [15].

In addition, Figure 2(a) shows that the kinetics of water absorption of extruded cereals elaborated with 5.0 and $7.5 \%$ of encapsulated powder were statistically different $(P<0.05)$ from control cereals and those with lower encapsulated powder content $(2.5 \%)$; the difference was observed after 40 min of soaking.

Milk absorption kinetics (Figure 2(b)) indicated a significant $(P<0.05)$ decrease in the capacity to absorb milk following an increase in the content of encapsulated powder added to the extrusion mixture. This reflected the trend seen for the WAI (Table 2) and water absorption kinetics (Figure 2(a)). Notably, the amount of absorbed water was twice as high $(P<0.05)$ as that of absorbed milk. This was caused by the sweet layer, with which the extruded cereal was coated and which protected it from softening. In addition, Figure 2(b) shows similar kinetics of milk absorption of extruded cereals with 2.5 and $5.0 \%$ of encapsulated powder. After $60 \mathrm{~min}$ of soaking, these kinetics were significantly different $(P<0.05)$ from control cereals and those with higher encapsulated powder content (7.5\%).

Under both conditions and even after 120 min of immersion, the extruded cereals had not reached maximum liquid absorption. This observation indicates that the cereals maintain their firmness or hardness for a long time, a characteristic desired by consumers who like crispy cereals.

Color is a very important quality parameter in extruded cereal or ready-to-eat cereal; this property is related to the acceptability of the product, as it is the first characteristic the consumer pays attention to. In this study, coloration of the extruded cereals was obtained using natural red-purple pigments. Table 3 shows the color parameters determined in the extruded cereal. All color parameters were significantly $(P<0.05)$ affected by the encapsulated powder added to the extrusion mixture.

As can be seen in Figure 1, the use of red cactus pear encapsulated powder changes drastically the color of the final product. The values of $L^{*}$ (luminosity) ranged from 61.3 to 89.5 and tended to decrease with an increase in the amount of encapsulated powder added. The parameter $b^{*}$ (bluenessyellowness) ranged from 21.9 to 52.8 and decreased with the addition of encapsulated powder. This decrease can be 
TABLE 3: Color parameters ${ }^{* *}$ of extrudates using encapsulated powder of red cactus pear (EPRCP) as pigment.

\begin{tabular}{lcccccc}
\hline EPRCP (\%) & $L^{*}$ & $a^{*}$ & $b^{*}$ & Croma $^{*}$ & $h^{\circ}$ \\
\hline 0 & $89.5 \pm 0.4^{\mathrm{a}}$ & $-3.7 \pm 0.1^{\mathrm{d}}$ & $52.8 \pm 0.3^{\mathrm{a}}$ & $52.9 \pm 0.3^{\mathrm{a}}$ & $85.9 \pm 0.1^{\mathrm{a}}$ & - \\
2.5 & $76.6 \pm 2.3^{\mathrm{b}}$ & $15.3 \pm 2.3^{\mathrm{c}}$ & $36.5 \pm 1.2^{\mathrm{b}}$ & $39.6 \pm 0.4^{\mathrm{b}}$ & $67.1 \pm 3.7^{\mathrm{b}}$ & $28.17 \pm 3.2^{\mathrm{c}}$ \\
5.0 & $67.6 \pm 0.9^{\mathrm{c}}$ & $27.2 \pm 0.5^{\mathrm{b}}$ & $25.7 \pm 0.3^{\mathrm{c}}$ & $37.5 \pm 0.6^{\mathrm{c}}$ & $43.3 \pm 0.3^{\mathrm{c}}$ & $46.68 \pm 0.5^{\mathrm{b}}$ \\
7.5 & $61.3 \pm 1.0^{\mathrm{d}}$ & $32.3 \pm 0.7^{\mathrm{a}}$ & $21.9 \pm 0.8^{\mathrm{d}}$ & $39.1 \pm 1.0^{\mathrm{b}}$ & $34.2 \pm 0.5^{\mathrm{d}}$ & $55.30 \pm 0.5^{\mathrm{a}}$ \\
\hline
\end{tabular}

${ }^{* *}$ Mean \pm standard deviation; mean with different letter by column represents significant $(P<0.05)$ difference by Tukey's test.

explained by a dilution of the yellow color of maize grits following an increase in the red coloration of the encapsulated powder. Alternatively, it could respond to a reduction of the yellow-orange components, such as betaxanthins and polyphenols, present in the encapsulated powder during the extrusion-cooking process $[8,10]$. This same effect was observed in extrudates obtained from maize flour and fruit powders [40]. In addition, chroma* (color intensity) and $h^{\circ}$ (color saturation) had values in the ranges of 39.1 to 52.9 and 34.2 to 81.9 , respectively. Both color parameters decreased with the increase in added encapsulated powder; this observation can be explained by both chroma* and $h^{\circ}$ being dependent on $a^{*}$ and $b^{*}$. With regard to $h^{\circ}$ values, the control extruded cereal exhibited a pure yellow color $\left(90^{\circ}\right)$, whereas the extruded cereal with added encapsulated powder had an $h^{\circ}$ that tended toward pure red or pure magenta $\left(0^{\circ}\right)$. With regard to $a^{*}$ (greenness-redness), this parameter increased along with the increase in the percentage of encapsulated powder in the mixture. This was to be expected given that the encapsulated powder has a high content of betalains, which have colors with a greater redpurple characteristic.

Color differences between extrudates of cereal without and with $2.5,5.0$, and $7.5 \%$ of encapsulated powder of red cactus pear were perceptible to the human eye (Figure 1) and were significantly different $(P<0.05)$. Table 3 shows that extruded cereal with higher amounts of added encapsulated powder had a greater color difference, and cereal with a lower encapsulated powder added had a smaller color difference. The same behavior regarding color parameters was reported in extruded snacks prepared with tomato pulp [15] and chestnut [30] and extrudates treated with cactus pear concentrates [14].

Another important quality feature in ready-to-eat cereal extrudates is texture; Table 4 shows the hardness and crispness values of extruded cereal. Hardness of the extruded cereals ranged from 9.81 to $59.47 \mathrm{~N}$, whereas crispness varied from 30.97 to $213.44 \mathrm{~N} \cdot \mathrm{mm}$; these values are in the range reported for rice-based expanded snacks [22]. The addition of encapsulated powder to maize grits caused an increase in both hardness and crispness of the extruded cereals; this may be due to the fact that as the encapsulated powder increased, fiber content also increased, rendering the resulting cereals less expanded and more dense (Table 2). This could be attributed to the fact that the fiber content in the mixture competes with starch for water at the outlet of the extruder, thereby restricting the process of starch gelatinization and dextrinization and allowing for more compact cereals $[14,37]$.
TABLE 4: Texture* of extrudates using encapsulated powder of red cactus pear (EPRCP) as pigment.

\begin{tabular}{lcc}
\hline EPRCP $(\%)$ & Hardness $(\mathrm{N})$ & Crispness $(\mathrm{N} \cdot \mathrm{mm})$ \\
\hline 0 & $9.81 \pm 2.13^{\mathrm{d}}$ & $30.97 \pm 5.75^{\mathrm{d}}$ \\
2.5 & $17.10 \pm 3.46^{\mathrm{c}}$ & $59.85 \pm 7.58^{\mathrm{c}}$ \\
5.0 & $37.51 \pm 5.26^{\mathrm{b}}$ & $151.27 \pm 5.87^{\mathrm{b}}$ \\
7.5 & $59.47 \pm 8.64^{\mathrm{a}}$ & $213.44 \pm 19.89^{\mathrm{a}}$ \\
\hline
\end{tabular}

${ }^{*}$ Mean \pm standard deviation; mean with different letter by column represents significant $(P<0.05)$ difference by Tukey's test.

This results in less porous matrices and harder and crisper extrudates. The same behavior has been reported for maizebased extrudates with added wheat fiber [37] and extruded snacks obtained using tomato pulp [15].

3.2. Chemical Analysis. The total contents of polyphenols, betacyanins, and betaxanthins as well as the antioxidant activity of mixtures before extrusion and of the obtained extruded cereals are shown in Figure 3. As expected, an increase in the content of encapsulated powder led to an increase in the total content of polyphenol, betacyanins, and betaxanthins, as well as antioxidant activity, before and after extrusion. However, when comparing the content of the above components before and after the extrusioncooking process, a reduction was observed. This finding is in agreement with previous reports [10], whereby the extrusion-cooking process caused a decrease in the levels of bioactive compounds, owing to both thermal- and highpressure-induced degradation and/or the increase of interactions between bioactive compounds and other components, such as proteins and starch [34]. The antioxidant activity was increased by the extrusion-cooking process, probably because of the release of some components present in the maize grits, since the nonpigmented extruded cereal exhibited the same effect.

3.3. Sensorial Analysis. The use of red cactus pear encapsulated powder for the pigmentation of extruded cereals has many benefits, as it contains soluble fiber and natural pigments with antioxidant activity. Nevertheless, the successful adaptation of the product depends on consumer acceptance. To address this, the cereals were sensorially evaluated for texture, color, taste, and odor attributes and a preference test was performed by a panel of consumer judges. The results obtained from this sensory analysis are presented in Figure 4. 

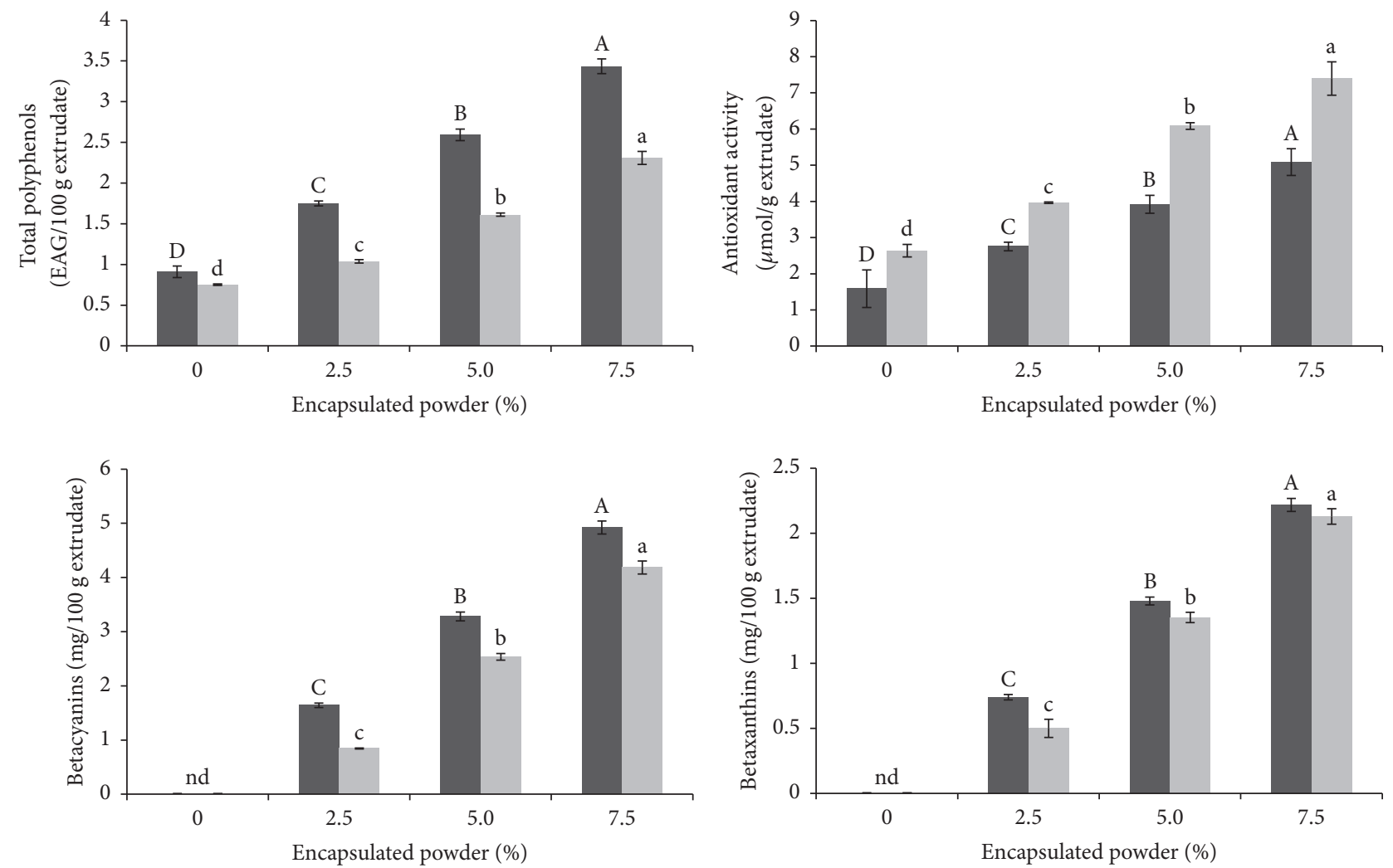

FIGURE 3: Total polyphenols, antioxidant activity, betacyanins, and betaxanthins: dark grey columns: mixture before extrusion-cooking process and grey columns: extruded cereal; using encapsulated powder of red cactus pear to pigment; different letter indicates significant difference $(P<0.05)$.

With regard to texture evaluation, the extruded cereals could be split in two groups: low content (0 and 2.5\%) and high content (5.0 and 7.5\%) of encapsulated powder. The latter were the hardest and were classified as neither like nor dislike (3), whereas the former presented the lowest measured hardness and were classified as like moderately (4) by the consumers. In the case of color, the most liked extruded cereals had a red color (7.5\% encapsulated powder), and the lowest liked had a pink color (2.5 and 5\% encapsulated powder, or control cereals). In terms of flavor, consumers preferred cereal without added powder and those with $2.5 \%$ of encapsulated powder; the lowest appeal was for cereal obtained with high content of red cactus pear (7.5\%). Regarding odor analysis, the majority of comments by consumer judges indicated that they failed to discern any special odor from the different cereals, but simply detected a corn smell from the extruded cereal samples.

Subsequently, consumers were asked to order the cereals according to their preference $(1=$ most preferred and $4=$ least preferred), when presented with the extruded cereal alone or accompanied with milk. Table 5 shows how the preference for the extruded cereal was affected by the mode of consumption. When tested alone, the cereal obtained with $2.5 \%$ encapsulated powder was the preferred one (1.6), having a more acceptable texture than the $5.0 \%$ and $7.5 \%$ formulations with values of 2.9 and 3.9 , respectively, and a more pleasing color than control cereal.

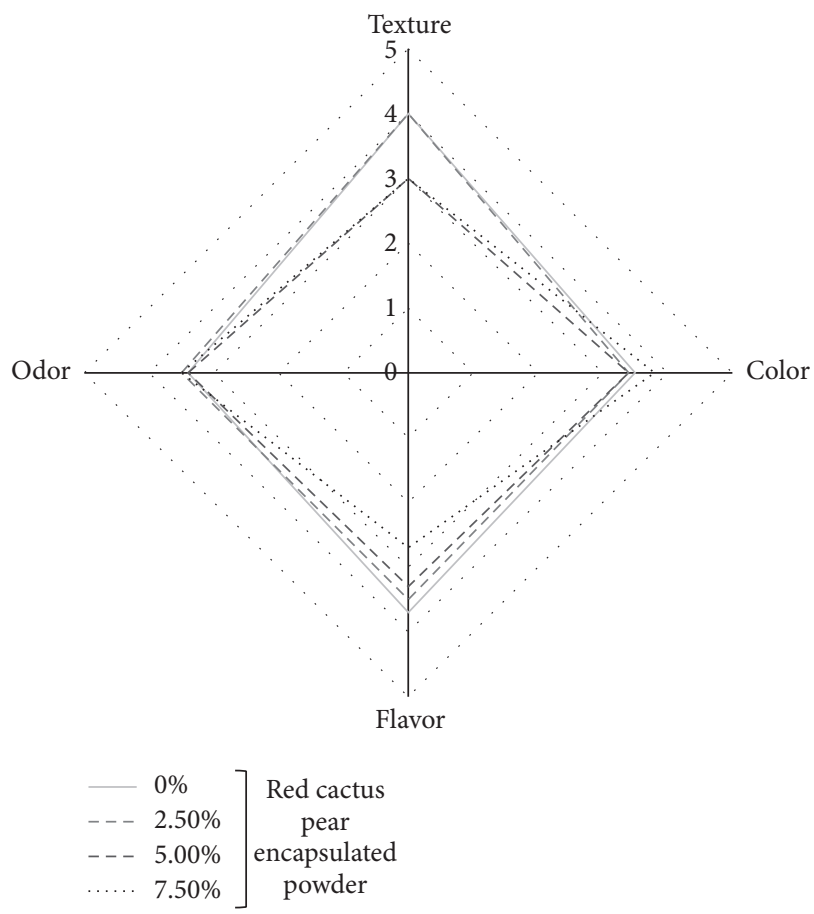

FIGURE 4: Sensory experience mapping on texture, color, flavor, and odor of extruded cereal pigmented with encapsulated powder of red cactus pear. 
TABle 5: Preference* ${ }^{*}$ of extrudate cereal pigmented used encapsulated powder of red cactus pear (EPRCP) as pigment.

\begin{tabular}{lcc}
\hline & \multicolumn{2}{c}{ Type of presentation } \\
EPRCP (\%) & Extrudate without milk & Extrudate with milk \\
\hline 0 & $2.1^{\mathrm{a}}$ & $2.0^{\mathrm{b}}$ \\
2.5 & $1.6^{\mathrm{b}}$ & $2.0^{\mathrm{b}}$ \\
5.0 & $2.9^{\mathrm{a}}$ & $3.0^{\mathrm{a}}$ \\
7.5 & $3.9^{\mathrm{a}}$ & $4.0^{\mathrm{a}}$ \\
\hline
\end{tabular}

${ }^{*}$ Median with different letter by column represents significance $(P<0.05)$ by Friedman's test. Preference test by order: $1=$ most preferred; $4=$ least preferred.

When consumed with milk, control cereals and those with $2.5 \%$ of encapsulated powder were deemed as having the most preferred texture (Table 5). According to the judges' comments, the texture of both cereal preparations was softer when soaked in milk, whereas the cereals with higher contents of red cactus encapsulated powder did not soften easily. This consumer finding is in agreement with the data obtained in the milk absorption kinetic study (Figure 2). These data showed higher milk absorption capacity in cereals with low encapsulated powder content (0 and 2.5\%) compared to cereals with a higher content (5.0 and 7.5\%). Even though the addition of 5.0 and $7.5 \%$ of encapsulated powder of red cactus pear did not have sufficient sensory acceptance due to the cereals' elevated hardness, addition of $2.5 \%$ encapsulated powder was preferred over nonpigmented cereal. Thus, this is an attractive extruded cereal because its coloration is natural, and it benefits from the presence of betalains and their antioxidant activity.

3.4. Correlation Analysis. Table 6 shows Pearson's coefficients. If the Pearson correlation is significant $(P<0.05)$, it indicates that two properties of the extruded cereal have a linear relationship. A positive correlation coefficient indicates the same behavior by two properties, which could be either an increase or a decrease. A negative correlation coefficient means that properties have opposite behavior: while the value of a characteristic increases the value of the other characteristic is reduced.

The bulk density of extruded cereal shows a positive correlation with physical properties, such as color parameter $a^{*}$, hardness, and crispness, as well as with contents of polyphenols, betacyanins and betaxanthins, and antioxidant activity. In contrast, the correlation with color parameters, such as $L^{*}, b^{*}$, chroma ${ }^{*}, h^{\circ}$, WAI, and WSI appears negative.

The WAI shows a positive correlation with expansion and water solubility indices, and color parameters $L^{*}, b^{*}, h^{\circ}$; but a negative correlation with contents of polyphenols, betacyanins and betaxanthins, antioxidant activity, bulk density, color parameter $a^{*}$, hardness, and crispness.

The color parameters $L^{*}, b^{*}$, chroma ${ }^{*}$, and $h^{\circ}$ exhibit the same positive correlations among themselves and with expansion index, WSI, and WAI; but negative correlations with respect to bulk density, hardness and crispness, and contents of polyphenols, betacyanins, betaxanthins, and antioxidant activity. Interestingly, the $a^{*}$ parameter shows a behavior that contrasts with that of other color parameters.

The texture properties hardness and crispness display the same positive correlations with bulk density and $a^{*}$ parameter but negative ones with color parameters $\left(L^{*}\right.$, $b^{*}$, chroma ${ }^{*}$, and $h^{\circ}$ ), expansion index, WSI, WAI, and contents of polyphenols, betacyanins and betaxanthins, and antioxidant activity.

The chemical properties (polyphenols, betacyanins and betaxanthins content, and antioxidant activity) display a positive correlation among themselves and with bulk density, hardness, crispness, and color parameter $a^{*}$ but a negative correlation with color parameters $L^{*}, b^{*}$, chroma ${ }^{*}$, and $h^{\circ}$, expansion index, WSI, and WAI.

\section{Conclusions}

The use of red cactus pear encapsulated powder at 2.5, 5.0 , and $7.5 \%(\mathrm{w} / \mathrm{w})$ significantly affected the physical and chemical properties of the resulting extruded cereal. The characteristics positively affected by an increased amount of encapsulated powder were water absorption index, milk absorption, color parameters, antioxidant activity, and total polyphenol, total betacyanin, and total betaxanthin content. In contrast, density and texture were negatively affected by an increase in the amount of encapsulated powder. From a sensorial perspective, consumers chose the extruded cereal containing $2.5 \%$ red cactus pear encapsulated powder, because its characteristics were similar to the control but had a better color. Cereal extrudates obtained with 5.0 and $7.5 \%$ of red cactus pear encapsulated powder had an attractive color but suffered from elevated hardness, with the least preference by consumers. These results show how addition of encapsulated powder in the formulation affected the physicochemical characteristics of extruded products, enhancing properties such as color and antioxidant activity. Accordingly, encapsulated powder of the red cactus pear can be a natural alternative to synthetic dyes and can be used to develop functional food with possible health benefits.

\section{Additional Points}

Practical Applications. There is a clear trend in consumer preference for clear food labeling and for food ingredients and additives whose names sound familiar to the consumer, because they are perceived to be organic/natural and therefore healthier. The use of natural ingredients represents a challenge for food product developers. Added pigments are an important part of commercial foods; however, the use of natural pigments has the disadvantage that they are less stable than their synthetic counterparts. In this study, we assessed the addition of betalain pigments such as red cactus pear encapsulated powder to the process of extruded cereal production and evaluated the physicochemical changes on the end-product. The results presented in this study establish that the use of 2.5 to $7.5 \%$ of red cactus pear encapsulated powder represents an alternative coloration and functional food procedure in high-temperature extrusion cooking. 


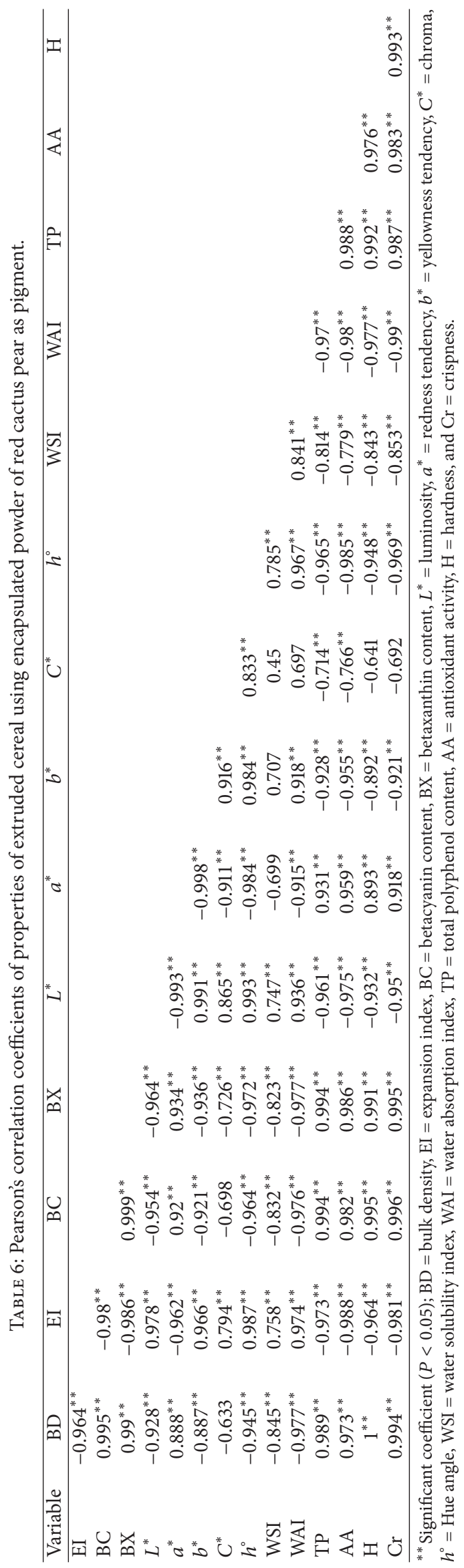




\section{Conflicts of Interest}

The authors declare that there are no conflicts of interest regarding the publication of this article.

\section{Acknowledgments}

The authors acknowledge the Universidad Autónoma de Nuevo León and the Universidad Autónoma de Chihuahua who supported this investigation. The Science and Technology National Council of Mexico provided a graduate study scholarship for Martha Graciela Ruiz-Gutiérrez.

\section{References}

[1] P. McDonagh, "Native, modified and clean label starches in foods and beverages," Natural Food Additives, Ingredients and Flavourings, pp. 162-174, 2012.

[2] R. Sánchez Juan, "La qu $\varphi$ mica del color en los alimentos," Qupmica Viva, vol. 12, no. 3, pp. 234-246, 2013.

[3] H. M. C. Azeredo, A. N. Santos, A. C. R. Souza, K. C. B. Mendes, and M. I. R. Andrade, "Betacyanin stability during processing and storage of a microencapsulated red beetroot extract," American Journal of Food Technology, vol. 2, no. 4, pp. 307-312, 2007.

[4] A. Patras, N. P. Brunton, B. K. Tiwari, and F. Butler, "Stability and Degradation Kinetics of Bioactive Compounds and Colour in Strawberry Jam during Storage," Food and Bioprocess Technology, vol. 4, no. 7, pp. 1245-1252, 2011.

[5] J.-C. Lee, K.-T. Lim, and Y.-S. Jang, "Identification of Rhus verniciflua Stokes compounds that exhibit free radical scavenging and anti-apoptotic properties," Biochimica et Biophysica Acta (BBA) - General Subjects, vol. 1570, no. 3, pp. 181-191, 2002.

[6] E. M. Galati, M. R. Mondello, D. Giuffrida et al., "Chemical characterization and biological effects of sicilian Opuntia ficus indica (L.) Mill. fruit juice: antioxidant and antiulcerogenic activity," Journal of Agricultural and Food Chemistry, vol. 51, no. 17, pp. 4903-4908, 2003.

[7] S. C. Sutter, M. P. Buera, and B. E. Elizalde, “ $\beta$-Carotene encapsulation in a mannitol matrix as affected by divalent cations and phosphate anion," International Journal of Pharmaceutics, vol. 332, no. 1-2, pp. 45-54, 2007.

[8] M. G. Ruiz-Gutiérrez, C. A. Amaya-Guerra, A. QuinteroRamos et al., "Effect of soluble fiber on the physicochemical properties of cactus pear (Opuntia ficus indica) encapsulated using spray drying," Food Science and Biotechnology, vol. 23, no. 3, pp. 755-763, 2014.

[9] F. Gandía-Herrero, J. Cabanes, J. Escribano, F. García-Carmona, and M. Jiménez-Atiénzar, "Encapsulation of the most potent antioxidant betalains in edible matrixes as powders of different colors," Journal of Agricultural and Food Chemistry, vol. 61, no. 18, pp. 4294-4302, 2013.

[10] M. G. Ruiz-Gutiérrez, C. A. Amaya-Guerra, A. QuinteroRamos et al., "Effect of extrusion cooking on bioactive compounds in encapsulated red cactus pear powder," Molecules, vol. 20, no. 5, pp. 8875-8892, 2015.

[11] S. K. El-Samahy, E. A. Abd El-Hady, R. A. Habiba, and T. E. Moussa-Ayoub, "Some functional, chemical, and sensory characteristics of cactus pear rice-based extrudates," Journal of the Professional Association for Cactus Development, vol. 9, pp. 136-147, 2007.
[12] M. Hirth, A. Leiter, S. M. Beck, and H. P. Schuchmann, "Effect of extrusion cooking process parameters on the retention of bilberry anthocyanins in starch based food," Journal of Food Engineering, vol. 125, no. 1, pp. 139-146, 2014.

[13] M. Hirth, R. Prei, E. Mayer-Miebach, and H. P. Schuchmann, "Influence of HTST extrusion cooking process parameters on the stability of anthocyanins, procyanidins and hydroxycinnamic acids as the main bioactive chokeberry polyphenols," LWT- Food Science and Technology, vol. 62, no. 1, pp. 511-516, 2015.

[14] R. C. Khanal, L. R. Howard, C. R. Brownmiller, and R. L. Prior, "Influence of extrusion processing on procyanidin composition and total anthocyanin contents of blueberry pomace," Journal of Food Science, vol. 74, no. 2, pp. H52-H58, 2009.

[15] A. Altan, K. L. McCarthy, and M. Maskan, “Twin-screw extrusion of barley-grape pomace blends: Extrudate characteristics and determination of optimum processing conditions," Journal of Food Engineering, vol. 89, no. 1, pp. 24-32, 2008.

[16] S. Yağci and F. Göğüş, "Response surface methodology for evaluation of physical and functional properties of extruded snack foods developed from food-by-products," Journal of Food Engineering, vol. 86, no. 1, pp. 122-132, 2008.

[17] A. Altan, K. L. McCarthy, and M. Maskan, "Effect of extrusion process on antioxidant activity, total phenolics and $\beta$-glucan content of extrudates developed from barley-fruit and vegetable by-products," International Journal of Food Science \& Technology, vol. 44, no. 6, pp. 1263-1271, 2009.

[18] E. Cortés-Ceballos, E. Pérez-Carrillo, and S. O. Serna-Saldívar, "Addition of sodium stearoyl lactylate to corn and sorghum starch extrudates enhances the performance of pregelatinized beer adjuncts," Cereal Chemistry, vol. 92, no. 1, pp. 88-92, 2015.

[19] A.O.A.C. Official Methods of Analysis of AOAC International, P. Cuniff, (Ed). A.O.A.C International. U. S.A Maryland, 1998.

[20] J. M. Harper, Extrusion of foods, CRC Press Inc, Boca Raton, 1981.

[21] T. C. Kha, M. H. Nguyen, and P. D. Roach, "Effects of spray drying conditions on the physicochemical and antioxidant properties of the Gac (Momordica cochinchinensis) fruit aril powder," Journal of Food Engineering, vol. 98, no. 3, pp. 385-392, 2010.

[22] Q.-B. Ding, P. Ainsworth, G. Tucker, and H. Marson, “The effect of extrusion conditions on the physicochemical properties and sensory characteristics of rice-based expanded snacks," Journal of Food Engineering, vol. 66, no. 3, pp. 283-289, 2005.

[23] M. F. Machado, F. A. R. Oliveira, V. Gekas, and R. P. Singh, "Kinetics of moisture uptake and soluble-solids loss by puffed breakfast cereals immersed in water," International Journal of Food Science \& Technology, vol. 33, no. 3, pp. 225-237, 1998.

[24] E. Pitalua, M. Jimenez, E. J. Vernon-Carter, and C. I. Beristain, "Antioxidative activity of microcapsules with beetroot juice using gum Arabic as wall material," Food and Bioproducts Processing, vol. 88, no. 2-3, pp. 253-258, 2010.

[25] A. Bucić-Kojić, M. Planinić, S. Tomas, M. Bilić, and D. Velić, "Study of solid-liquid extraction kinetics of total polyphenols from grape seeds," Journal of Food Engineering, vol. 81, no. 1, pp. 236-242, 2007.

[26] E. M. Kuskoski, A. G. Asuero, A. M. Troncoso, J. Mancini-Filho, and R. Fett, "Aplicación de diversos métodos químicos para determinar actividad antioxidante en pulpa de frutos," Ciência e Tecnologia de Alimentos, vol. 25, no. 4, pp. 726-732, 2005.

[27] E. Castellanos-Santiago and E. M. Yahia, "Identification and quantification of betalains from the fruits of 10 Mexican prickly 
pear cultivars by high-performance liquid chromatography and electrospray ionization mass spectrometry," Journal of Agricultural and Food Chemistry, vol. 56, no. 14, pp. 5758-5764, 2008.

[28] Minitab 17, Statistical Software, Minitab, Inc., State College, PA, USA, 2014.

[29] J. M. Hashimoto and M. V. E. Grossmann, "Effects of extrusion conditions on quality of cassava bran/cassava starch extrudates," International Journal of Food Science \& Technology, vol. 38, no. 5, pp. 511-517, 2003.

[30] G. Sacchetti, G. G. Pinnavaia, E. Guidolin, and M. D. Rosa, "Effects of extrusion temperature and feed composition on the functional, physical and sensory properties of chestnut and rice flour-based snack-like products," Food Research International, vol. 37, no. 5, pp. 527-534, 2004.

[31] L. F. Wen, P. Rodis, and B. P. Wasserman, "Starch fragmentation and protein insolubilization during twin-screw extrusion of corn meal," Cereal Chemistry, vol. 67, pp. 228-275, 1990.

[32] Z. Jin, F. Hsieh, and H. E. Huff, "Extrusion cooking of corn meal with soy fiber, salt and sugar," Cereal Chemistry, vol. 71, pp. 227234, 1994.

[33] Y. Andersson, L. Hedlund, and S. Svensson, "Extrusion of a highfiber cereal product with crispbread character," Cereal Chemistry, vol. 58, no. 5, pp. 370-374, 1981.

[34] N. Bordenave, B. R. Hamaker, and M. G. Ferruzzi, "Nature and consequences of non-covalent interactions between flavonoids and macronutrients in foods," Food \& Function, vol. 5, no. 1, pp. 18-34, 2014.

[35] J. W. Vargas-Solórzano, C. W. P. Carvalho, C. Y. Takeiti, J. L. R. Ascheri, and V. A. V. Queiroz, "Physicochemical properties of expanded extrudates from colored sorghum genotypes," Food Research International, vol. 55, pp. 37-44, 2014.

[36] S. Lue, F. Hsieh, I. C. Peng, and E. H. Huff, "Expansion of corn extrudates containing dietary fiber: A microstructure study," Lebensmittel-Wissenschaft and Technologie, vol. 23, pp. 65-173, 1990.

[37] S. Yanniotis, A. Petraki, and E. Soumpasi, "Effect of pectin and wheat fibers on quality attributes of extruded cornstarch," Journal of Food Engineering, vol. 80, no. 2, pp. 594-599, 2007.

[38] Y. Ali, M. A. Hanna, and R. Chinnaswamy, "Expansion characteristics of extruded corn grits," LWT-Food Science and Technology, vol. 29, no. 8, pp. 702-707, 1996.

[39] F. Barros, J. M. Awika, and L. W. Rooney, "Interaction of tannins and other sorghum phenolic compounds with starch and effects on in vitro starch digestibility," Journal of Agricultural and Food Chemistry, vol. 60, no. 46, pp. 11609-11617, 2012.

[40] M. E. Camire, M. P. Dougherty, and J. L. Briggs, "Functionality of fruit powders in extruded corn breakfast cereals," Food Chemistry, vol. 101, no. 2, pp. 765-770, 2007. 

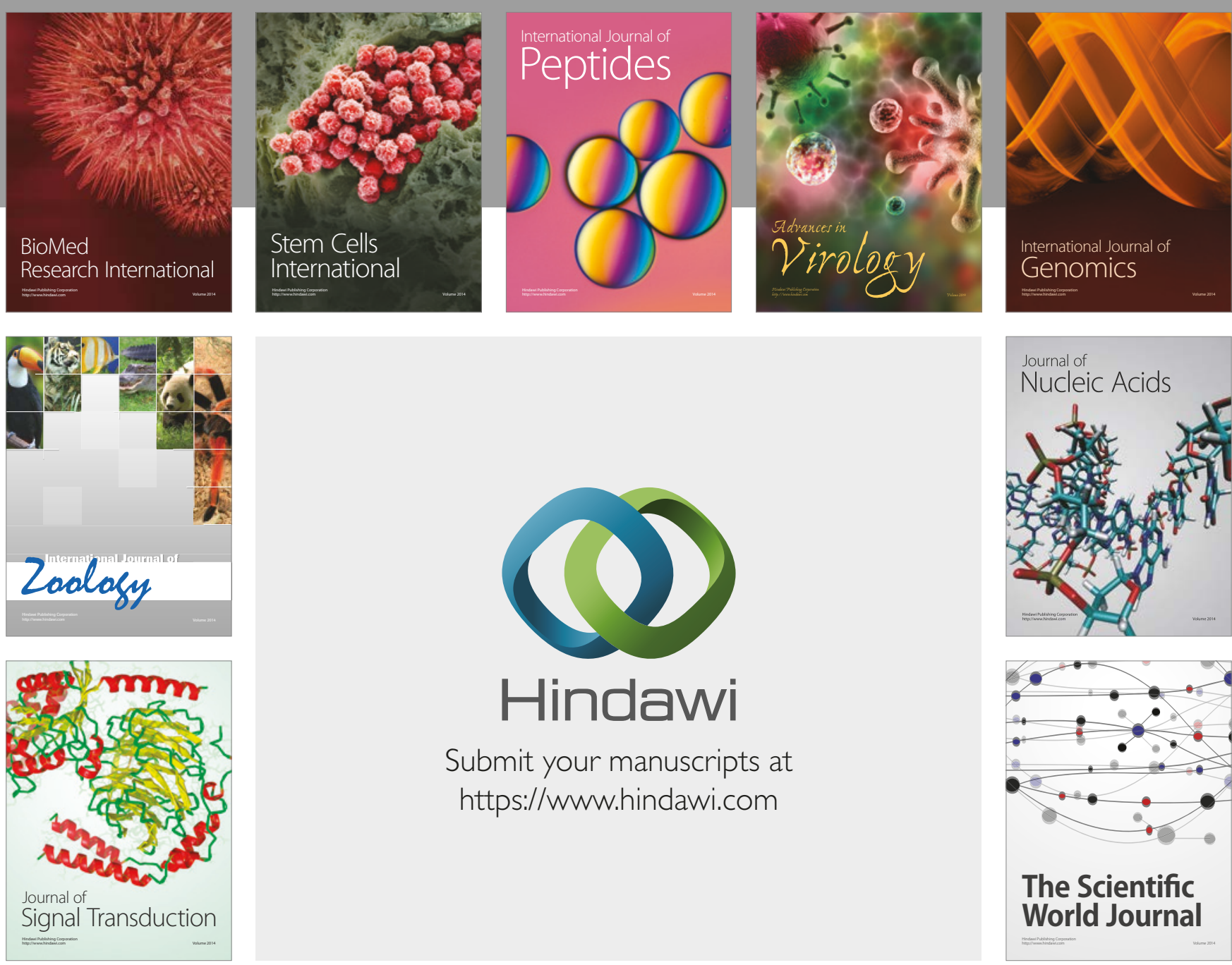

Submit your manuscripts at

https://www.hindawi.com
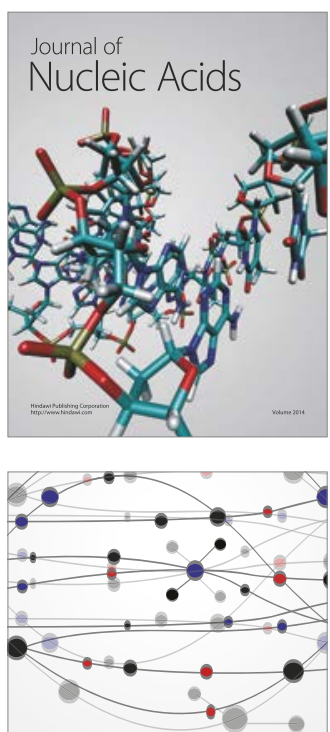

The Scientific World Journal

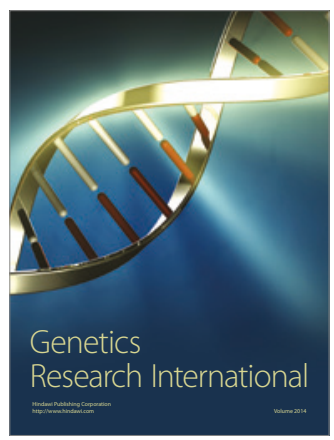

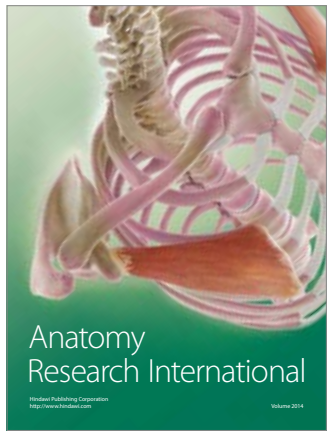

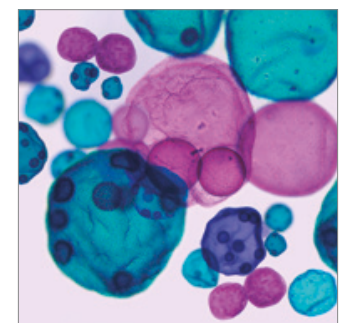

International Journal of Microbiology
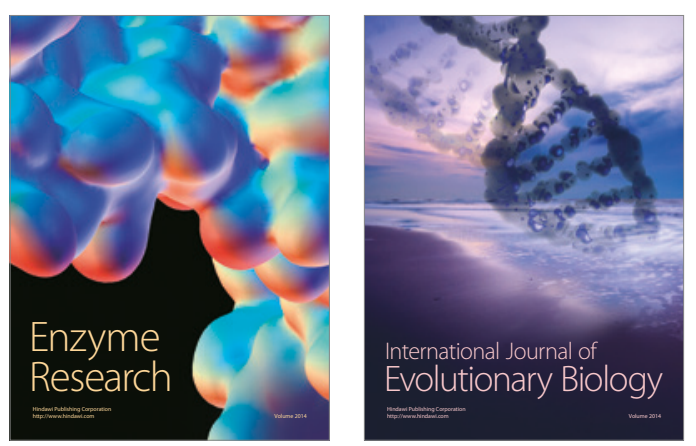
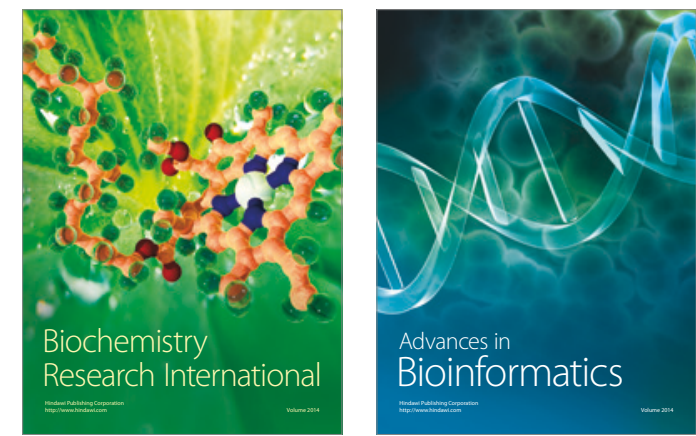

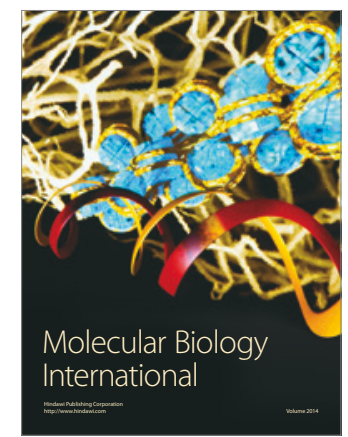

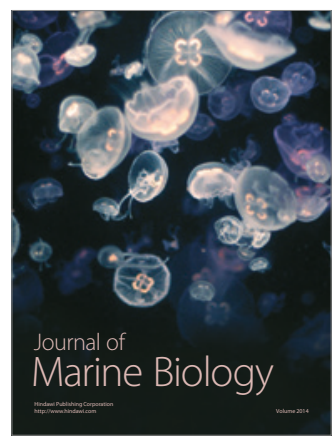

